\title{
Abordagens da multiplicação em livros didáticos produzidos no Rio Grande Do Sul (1960-1978)
}

Antônio Maurício Medeiros Alves

\section{Resumo}

Em meados do século XX um importante movimento de renovação do ensino da Matemática se desenvolveu mundialmente, influenciando os saberes profissionais dos professores e a produção didática para o ensino dessa disciplina. Considerando a importância dos livros didáticos como fonte de saberes para os professores, esse texto apresenta um estudo sobre as transformações, decorrentes do Movimento da Matemática Moderna, que geraram diferentes abordagens da operação da multiplicação em três coleções de livros didáticos produzidos no Rio Grande do Sul, para o ensino primário, no período de 1960-1978: Estrada Iluminada e Nossa Terra Nossa Gente (em duas versões). O estudo, de cunho histórico, privilegiou a análise documental de dezessete volumes de livros das coleções citadas e adota como referencial teórico-metodológico a História Cultural, a partir de autores como Roger Chartier. Tem por principal objetivo analisar as mudanças de abordagem da operação da multiplicação nos livros das coleções citadas. Verificou-se que a operação da multiplicação teve sua abordagem modificada em função de um novo conteúdo, a Teoria dos Conjuntos.

Palavras-chave: Livro Didático; Matemática Moderna; Ensino Primário; Multiplicação. 


\section{Multiplication approaches in didactic books produced in Rio Grande Do Sul (1960-1978)}

Antônio Maurício Medeiros Alves

\section{Abstract}

In the middle of the XX century an important worldwide movement was developed, It is about a renewal of Mathematics teaching, this movement influenced the professional knowledge of the teachers and the didactic production of this subject. Considering that textbooks are important sources of knowledge for teachers, this text presents a study about transformations arising from the New Math Movement that engendered different approaches to the multiplication operation in three collections of textbooks produced in Rio Grande do Sul , for primary education, in the period between 1960-1978: "Estrada Iluminada" and "Nossa Terra Nossa Gente" (in two versions). The historical study privileged the documentary analysis of seventeen volumes of the mentioned collections and adopted as reference the Cultural History, from authors like Roger Chartier. The purpose of this text is to analyze the changes in approach to the operation of multiplication in the books of the cited collections. It was verified that the operation of the multiplication had its approach modified because of a new content, the Theory of Sets.

Keywords: Textbooks; New Math; Primary education; Multiplication. 


\section{Introdução}

Esse trabalho apresenta parte de uma pesquisa maior (tese de doutorado) cujo objetivo central foi a análise da produção, circulação e utilização da produção didática gaúcha destinada ao uso no ensino primário e séries iniciais do ensino de $1^{\circ}$ grau (especialmente entre os anos de 1940-1980).

Considerando a importância e influências do Movimento da Matemática Moderna (MMM) nas práticas dos professores que ensinam Matemática, surge o desejo de realizar um estudo sobre esse movimento e seu desenvolvimento no estado do Rio Grande do Sul. Na busca da construção do objeto de pesquisa para a tese, foi realizada a leitura de diferentes trabalhos acadêmicos produzidos no âmbito da História da Matemática Escolar, o que permitiu identificar uma lacuna relativamente às pesquisas que contemplam as implicações do MMM em relação ao Ensino Primário e, em particular, a esse nível de ensino no Rio Grande do Sul, bem como às produções didáticas desse estado.

Ciente da importância dos livros didáticos como suportes veiculadores dos saberes docentes desenvolvidos pelos professores em suas práticas escolares, essa lacuna, por si só, já justificaria a realização da pesquisa aqui parcialmente apresentada. Entretanto, somou-se a esse fato - na definição do objeto de estudo, da problemática e dos objetivos específicos da pesquisa - outros elementos, dentre os quais destaca-se compreender como a Matemática Moderna foi incorporada aos livros didáticos produzidos para o Ensino Primário no Rio Grande do Sul. Essas foram as razões que despertaram o interesse em propor uma pesquisa qualitativa de cunho histórico, que contemplasse os livros didáticos produzidos nesse estado, problematizando sua importância e papel didático na história da Educação Matemática.

Dentre os elementos desenvolvidos na tese, pode-se destacar o estudo das mudanças na abordagem de conteúdos da Matemática do Ensino Primário, tendo esse texto por objetivo analisar as mudanças de abordagem da operação da multiplicação, importante conteúdo desse nível de ensino.

O estudo considerou como objetos e fontes de pesquisa, três coleções didáticas produzidas no Rio Grande do Sul no período de 1960 a 1978: a coleção Estrada Iluminada (EI) e as coleções Nossa Terra Nossa Gente (em dois formatos, nomeados como NTNG_1 e NTNG_2). As coleções fazem parte do acervo físico do Grupo de pesquisa História da Alfabetização, Leitura, Escrita e dos Livros Escolares (HISALES). Essas coleções foram definidas como objetos de estudo por diferentes motivos, dentre os quais se destacam a relevância de suas autoras - Cecy Cordeiro Thofehrn e Nelly Cunha Nelly Cunha (PERES, 2006) - na produção didática gaúcha, e o período em que foram produzidas, paralelamente ao Movimento da Matemática Moderna (MMM), importante momento histórico de renovação do ensino da Matemática. 


\section{Desenvolvimento}

O estudo desenvolvido na pesquisa maior teve por objetivo maior compreender como a Matemática Moderna foi incorporada nas coleções "Nossa Terra Nossa Gente" a partir da reelaboração da coleção "Estrada Iluminada”. Já esse texto apresenta os resultados do estudo especificamente em relação à operação aritmética da multiplicação.

Os livros da coleção "Estrada Iluminada", conforme encontrado na página de rosto dos exemplares, fazem parte da "Coleção Didática do Brasil - Série Nelci” ( $1^{\circ}$ ao $4^{\circ}$ ano). Podese afirmar que essa coleção foi produzida no início da década de 1960, a partir de "traços indiretos" que os livros apresentam, como as datas dos exemplares localizados (CHOPPIN, 2002). Foram editados livros destinados do $1^{\mathrm{o}}$ ao $4^{\mathrm{o}}$ ano do ensino primário, no formato de $13 \times 18 \mathrm{~cm}$, com dimensões comumente utilizadas nesse período (BATISTA, 2009) e com impressão monocromática (somente preto), nos textos do miolo, sobre papel tipo jornal encerado e uso de cor apenas nas capas. Cada livro recebe um "subtítulo" diferente, expresso na capa, abaixo do nome da coleção.

Já a coleção "Nossa Terra Nossa Gente” foi inicialmente editada no formato 14x21 cm, como parte da "Coleção Didática do Brasil - Série Primária”. Os exemplares localizados não apresentam data, porém o fato de ser dirigida ao Ensino Primário (indicado nos livros) permite identificar sua publicação como anterior a 1971, pois a Lei de Diretrizes e Bases 5692/71 extinguiu o Ensino Primário e instituiu o de $1^{\circ}$ grau.

Essa coleção apresenta os conteúdos de Linguagem, Matemática Moderna, Estudos Sociais e Moral e Cívica, organizados em cinco volumes. Os livros da coleção "Nossa Terra Nossa Gente", lançados no início da década de 1970 (NTNG_1), tiveram uma reedição NTNG_2 - entre os anos de 1974 e 1975, como revelam as datas das edições mais antigas, formando, portanto, uma nova coleção. Todos os livros que pertencem a essa coleção e que compõem o corpus da pesquisa apresentam, no verso da página de rosto, a indicação de que foram revisados e atualizados de acordo com a reforma do ensino, provavelmente numa referência à Lei 5692/71.

Tendo estabelecido a análise documental como metodologia a ser empregada na investigação, a periodização para o trabalho e, principalmente, os livros didáticos que iriam compor o corpus do estudo, passei ao tratamento das fontes, a fim de construir os dados da pesquisa. Foram reunidas as fontes suficientes para o início da tarefa de análise propriamente dita, com um total de cinquenta e dois livros das coleções "Estrada Iluminada" e "Nossa Terra Nossa Gente". Essa análise foi realizada, inicialmente, por meio de uma leitura de identificação, nomeada como análise horizontal das fontes, na qual foram comparadas as diferentes edições disponíveis de cada livro.

Para tanto, foram reunidos, por exemplo, todos os livros da coleção "Estrada ISSN 2526-2882 
Iluminada", relativos ao $1^{\circ}$ Ano do Ensino Primário, em suas diferentes edições, com o propósito de verificar se havia mudanças significativas entre essas edições.

Esse trabalho foi realizado com uma leitura simultânea dos livros, de modo a permitir uma efetiva comparação entre as edições. O processo de análise horizontal dos livros em suas diferentes edições, apesar de bastante cansativo, permitiu a redução das obras que seriam analisadas em uma próxima etapa, para dezessete exemplares.

Considerando a possibilidade de uma análise serial indicada por Choppin (2002), foi iniciado o processo que chamei de análise vertical das fontes, por meio da qual foram comparados os livros de uma mesma série, mas de diferentes coleções. Essa foi, então, a segunda análise, agora realizada nos dezessete livros resultantes após a análise horizontal.

Durante a análise vertical das fontes, foram buscadas permanências e alterações nas propostas didáticas dos livros, as quais foram sendo registradas para futura apresentação e análise em busca dos motivos que levaram as autoras a proporem as mudanças identificadas, relacionando-as, sempre que possível, aos princípios do MMM, definidos na leitura das obras de referência.

Pela análise dos livros, foi possível identificar quais conteúdos da Matemática Moderna foram contemplados na reelaboração de tais coleções, identificando a influência desse movimento na produção didática gaúcha e confirmando a importância dos livros didáticos como fonte para a História da Educação Matemática.

A partir dessa análise vertical foram construídos os dados para a pesquisa, cuja interpretação foi realizada considerando quatro princípios (categorias) identificados nas leituras das obras de referência do MMM: Teoria dos Conjuntos, operações aritméticas, estudo das relações e estruturas topológicas. Como já anunciado, nesse texto serão abordadas questões referentes somente à categoria operações aritméticas, focando a operação de multiplicação, especificamente.

\section{O estudo das operações aritméticas nos livros didáticos: diferentes abordagens da multiplicação}

No estudo desenvolvido na pesquisa é apresentado um capítulo sobre um dos princípios fundamentais do MMM eleito como categoria de análise dos livros didáticos, a Teoria dos Conjuntos. Os dados permitiram identificar uma importante mudança na abordagem da numeração no Ensino Primário, decorrente do novo modelo pedagógico proposto, conhecido como Matemática Moderna, no qual a noção de número deixou de ser desenvolvida por meio de práticas de contagem e passou a ser trabalhada a partir da compreensão de que o número é uma propriedade dos conjuntos.

Dessa forma, é compreensível que figure entre os princípios do MMM o ensino das ISSN 2526-2882

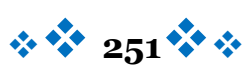


operações aritméticas por meio das operações que podem ser estabelecidas entre dois ou mais conjuntos. De fato, essas são as orientações encontradas nas obras de Dienes (1967), importante autor de referência do MMM. Segundo o autor, o trabalho com as classes de primário deve contemplar, inicialmente, o conceito de número a ser apresentado às crianças como uma propriedade dos conjuntos, segundo a qual, o número de elementos de um conjunto será representado por um algarismo. Após as crianças dominarem essa abstração, o autor indica que se deve passar ao estudo das operações:

A fase seguinte, no processo de aprendizagem, impõe-se naturalmente como devendo ser a da construção das operações sobre os conjuntos. Uma vez entendidas as distinções entre números e conjuntos, igualdade de números, conjunto vazio e número zero, torna-se possível enxertar a noção de adição sobre a de reunião de conjuntos (DIENES, 1967, p. 54).

Considerando todos os motivos anteriormente apresentados, a proposta desse artigo é analisar as mudanças de abordagem da operação da multiplicação nos livros didáticos, considerando-se as propostas de renovação do ensino de Matemática decorrentes do MMM.

O trabalho com as quatro operações tem início logo que o conceito de número é explorado e sistematizado, ou seja, nos primeiros anos escolares, o que implicou numa análise, mais criteriosa, das operações aritméticas nos livros do $1^{\circ}$ e $2^{\circ}$ ano do primário. Dessa forma, a maioria dos dados produzidos e apresentados refere-se à análise destes livros. Nos casos em que a análise dos livros, das demais séries, indicou a abordagem das operações de forma significativa, em relação aos objetivos desse trabalho, os mesmos foram incluídos.

Ao comparar as coleções NTNG_1 e NTNG_2 notei que as operações entre conjuntos somente são apresentadas após a exploração de diversos exercícios que propõem o estudo das propriedades numéricas 97 dos conjuntos, bem como, dos conceitos de conjunto vazio e unitário e, ainda, das relações entre elementos e conjuntos, comprovando a influência dos estudos de Dienes nessas coleções.

As orientações de Dienes podem ser identificadas no Livro do Mestre da coleção NTNG_2, especialmente nas palavras que as autoras dirigem aos professores, indicando que o princípio do MMM que relaciona as operações aritméticas às operações entre conjuntos, embasa os exercícios propostos. Elas apresentam a seguinte orientação aos professores:

A operação de união deve ser vivenciada através de jogos realizados no pátio da escola. [...] Poderão construir conjuntos de botões grandes e de botões

\footnotetext{
97 Entende-se por propriedade numérica de um conjunto a representação da quantidade de elementos desse conjunto. Assim, por exemplo, dizemos que um conjunto com 3 elementos apresenta como propriedade numérica o número 3. O estudo das propriedades numéricas dos conjuntos inclui, ainda, a comparação entre a quantidade de elementos de dois ou mais conjuntos e a representação de conjuntos a partir da definição do número de elementos que o compõe.
} 
pequenos, por exemplo, limitando-os com cordões. Depois, atarão outro cordão reunindo os dois conjuntos. [...] O conjunto união é formado de todos os botões grandes ou de todos os botões pequenos. Associando numerais ao número de elementos dos conjuntos, realizarão a operação de adição (THOFEHRN e CUNHA, 1974, p. 12).

Nessas orientações há a influência dos estudos da Psicologia realizados por Piaget e Inhelder (1975), que defendiam que o desenvolvimento intelectual da criança estaria relacionado às ações concretas do sujeito, o que justifica a proposta, presente nos livros, da realização de jogos, nos quais os alunos poderiam agir e refletir sobre suas ações.

Através da análise dos conteúdos dos livros, verifiquei que a partir dos volumes do $2^{0}$ ano do Ensino Primário, há uma mudança gradual entre as abordagens da multiplicação nas três coleções analisadas, que permitem identificar a coleção NTNG_1 como uma coleção transitória, na qual elementos da proposta "tradicional" e da "moderna" se fazem presentes, em proporções variáveis.

Tanto o livro do $2^{\circ}$ ano da coleção EI, quanto da coleção NTNG_1, utilizam o mesmo argumento para induzir o aluno à construção do conceito de multiplicação como a soma de parcelas repetidas, ideia que está presente nas propostas dos exercícios das coleções EI e NTNG_1, exemplificados nas Figuras 01 e 02.

Figura 01 - EI - $2^{\circ}$ ano (1960, p. 69).

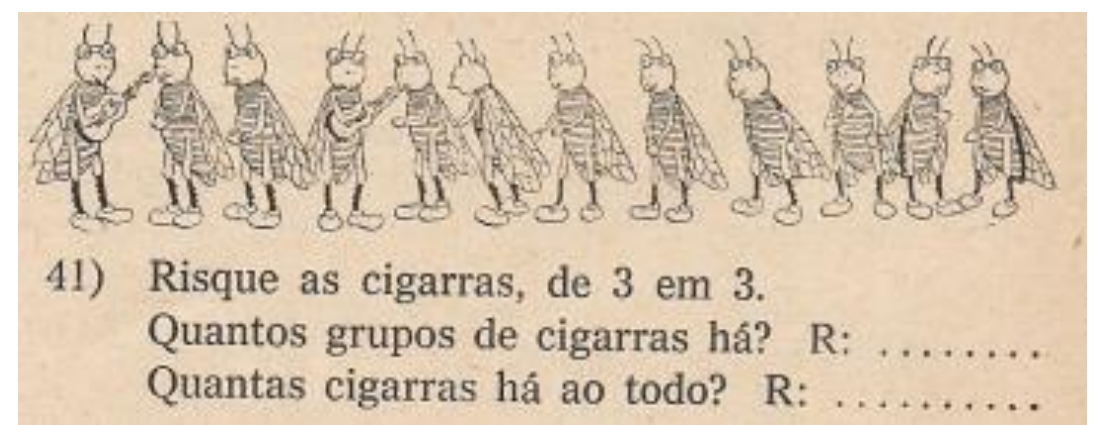

Fonte: Acervo do HISALES

Figura 02 - NTNG_1 - $2^{\circ}$ ano (s/d, p. 163).

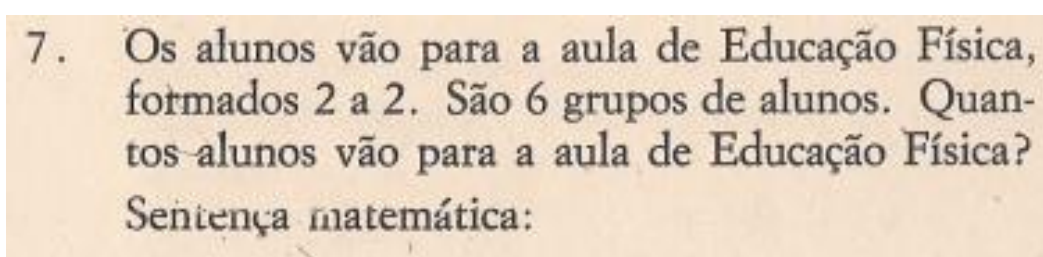

Resp.

Fonte: Acervo do HISALES

A semelhança entre essas propostas me permite afirmar que as autoras mantiveram, I I I $\angle J \angle 0-\angle O \delta<$ 
em alguma medida, a mesma abordagem nos dois livros, pois, embora o primeiro utilize a representação gráfica (imagem das cigarras) e texto escrito, e o segundo use somente o texto, o princípio em ambos é o mesmo: a repetição de grupos com mesmo número de elementos. No exercício das "cigarras" são identificados quatro grupos com três cigarras em cada um deles, o que deveria fazer com que o aluno compreendesse que o número total de cigarras pode ser definido pela soma $3+3+3+3$, o que equivale a $4 \times 3$. Já no exercício 7 , são seis grupos de dois alunos cada, ou seja, $2+2+2+2+2+2$, o que é o mesmo que 6x2. Assim, mesmo com representações diferentes (imagem e texto), ambos os livros apresentam a mesma ideia subjacente ao conceito de multiplicação: a soma de parcelas iguais.

A multiplicação, nesses livros, é apresentada aos alunos a partir de problemas envolvendo situações multiplicativas, explorando a notação dessa operação para traduzir o problema da língua vernácula para a linguagem matemática, como se percebe nos exemplos apresentados. Apesar do livro do $3^{\circ}$ ano da coleção EI, lançado em 1967, já apresentar elementos da Matemática Moderna nos exercícios, essa ideia tradicional para multiplicação é apresentada explicitamente nesse exemplar, como está ilustrado na Figura o3.

Figura 03 - EI - $3^{\circ}$ ano (1967, p. 124).

4) Carlos Roberto ajuda a arrumar as classes de sua sala de aula. Coloca 4 classes em 6 filas.

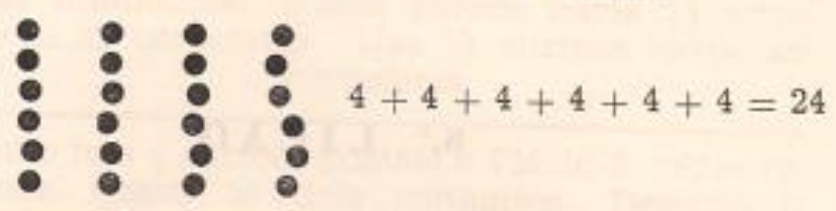

A soma 24 recebe o nome de produto.

Produto é o resultado de uma multiplicação.

Multiplicar é somar parcelas iguais.

Fonte: Acervo do HISALES

Entretanto, apesar da forma tradicional pela qual é abordada a multiplicação no livro da coleção NTNG_1, no Manual do Professor, referente ao livro do $4^{\circ}$ ano, são contemplados princípios da proposta modernizadora para o ensino dessa operação, como ilustra a Figura 04. 
Figura 04 - Manual do Professor - NTNG_1 - $4^{\mathrm{o}}$ ano (s/d, p. 44).

Os alunos, reunindo conjuntos equivalentes, descobrirão a multiplicação. Por exemplo, o professor desenhará no quadro os seguintes conjuntos e pedirá aos alunos que os reunam.
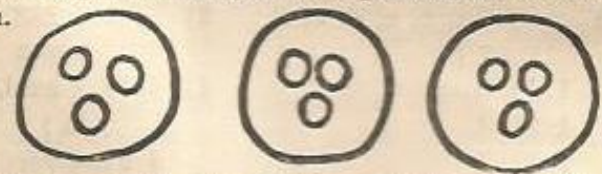

Os alunos passarão uma volta em tôrno aos três conjuntos e contarão os elementos dos conjuntos reunidos.

A divisão será dada a partir da participação de conjuntos ou subconjuntos equivalentes.

Os alunos devem compreender que a divisão é a operação inversa da multiplicação, que a multiplicação faz e a divisão desfaz.

$$
-44-
$$

\section{Fonte: Acervo do HISALES}

A proposta revelada no Manual do Professor atende às orientações de Dienes (1967) para o ensino da multiplicação, pois o autor argumenta que "a consideração de conjuntos conduzirá à operação aritmética da multiplicação” (p. 57), assim exemplificado:

Suponhamos que constituímos quatro conjuntos de três feijões cada um: a propriedade número de cada conjunto de feijões é 3 (aqui, contam-se feijões);

a propriedade número do conjunto de feijões é 4 (aqui contam-se conjuntos);

a propriedade número do conjunto de todos os feijões é 12 (voltam-se agora a contar feijões) (DIENES, 1967, p. 57-58).

Através da análise do Manual do Professor (THOFEHRN, CUNHA, s/d) e pela relação identificada entre o exemplo das autoras e o de Dienes (1967), fica também explicitada a sua influência na produção da coleção NTNG_1. No livro do $2^{\circ}$ ano aparece a abordagem "moderna" da multiplicação, baseada na Teoria dos Conjuntos, como se percebe na Figura 05.

Figura $05-N T N G \_1-2^{\mathrm{o}}$ ano (s/d, p. 161).

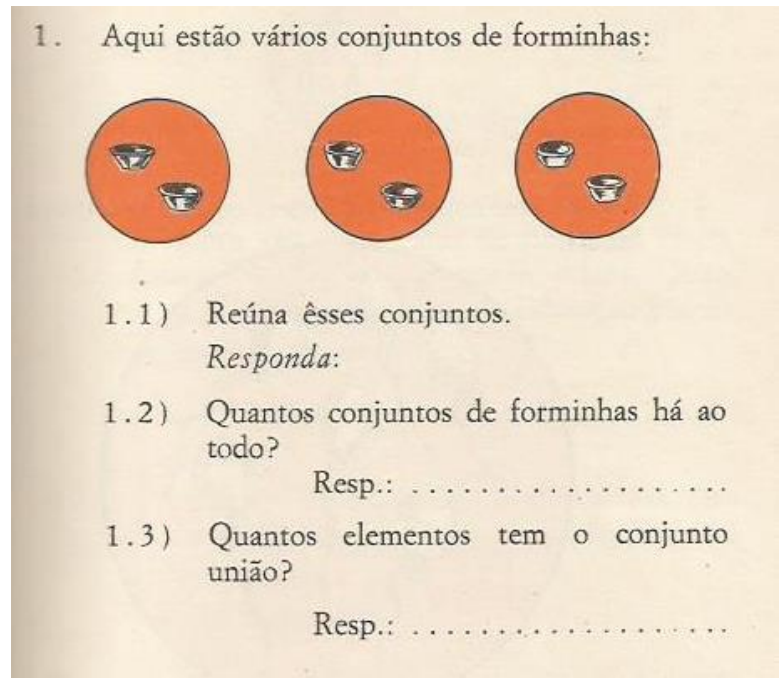

Fonte: Acervo do HISALES

ISSN 2526-2882 
A mesma abordagem verificada no exemplo da Figura 05 está também nos livros da coleção NTNG_2. As orientações de Dienes (1967) são reproduzidas no Livro do Mestre (THOFEHRN e CUNHA, 1975) que acompanha os livros dessa coleção, cuja imagem é ilustrada na Figura 06.

Figura 06 - Livro do Mestre - NTNG_2 (1975, p. 89).

\section{UNIDADE}

Objetivos: Identificação das operaçoes: multiplicação e divisăo com números naturais. Identificaçăo das propriedades da matéria.

Segundo Dienes, "a consideraçăo de conjuntos de conjuntos conduzirá à operaçắo aritmética de multiplicação". E, exemplificando: "Poderemos formar, por exemplo, um universo com um monte de feijōes; outro universo será o de todos os conjuntos (grandes e pequenos) que se possam extrair do primitivo universo de feijôes. Para sublinhar a natureza diferente desses conjuntos podemos colocá-los em pratos ou quaisquer outros recipientes. Suponhamos que constituímos quatro conjuntos de três feijões cada um:

a propriedade-número de cada conjunto de feijôes é 3 (aqui, contam-se feijões);

a propriedade-número do conjunto de feijões é 4 (aqui contam-se conjuntos);

a propriedade-número do conjunto de todos os feijōes

é 12 (voltam agora a contar-se os feijóes)."

Os alunos poderăo formar 4 conjuntos com 7 elementos cada um. Com um cordão contornarão os conjuntos construídos.

Observarão:

$$
\begin{aligned}
& \text { Número de conjuntos } \longrightarrow \begin{array}{r}
4 \\
\text { Número de elementos de cada conjunto } \longrightarrow \\
\text { Número total de elementos } \longrightarrow 28
\end{array}
\end{aligned}
$$

A multiplicação também deverá ser estudada através do produto cartesiano.

O professor poderá propor à classe problemas surgidos de situações reais, como por exemplo:

89

Fonte: Acervo do HISALES

As professoras-autoras revelam-se, assim, "leitoras" da obra de Dienes (1967), o que reforça sua influência na produção da coleção Nossa Terra Nossa Gente, pois, além da referência aos seus livros na bibliografia dessa coleção e dos indícios de suas orientações encontrados na análise dos livros da coleção NTNG, elas reproduzem, diretamente da fonte, o exemplo de Dienes (1967, p. 58) para o ensino da multiplicação (Figura 06).

Um exemplo de exercício, bastante semelhante ao que Dienes (1967) propõe, presente nos livros da coleção NTNG_1 é ilustrado na Figura 07, no qual há a substituição dos “feijões", do exemplo de Dienes (1967, p. 58), por flores, devendo ser assim interpretado: a propriedade 
número de cada conjunto de flores é 5 (aqui, contam-se flores); a propriedade número do conjunto de flores é 3 (aqui contam-se conjuntos); a propriedade número do conjunto de todas as flores é 15 (voltam-se agora a contar flores).

Figura 07 - NTNG_1 - $2^{\mathrm{o}}$ ano (s/d, p. 166).

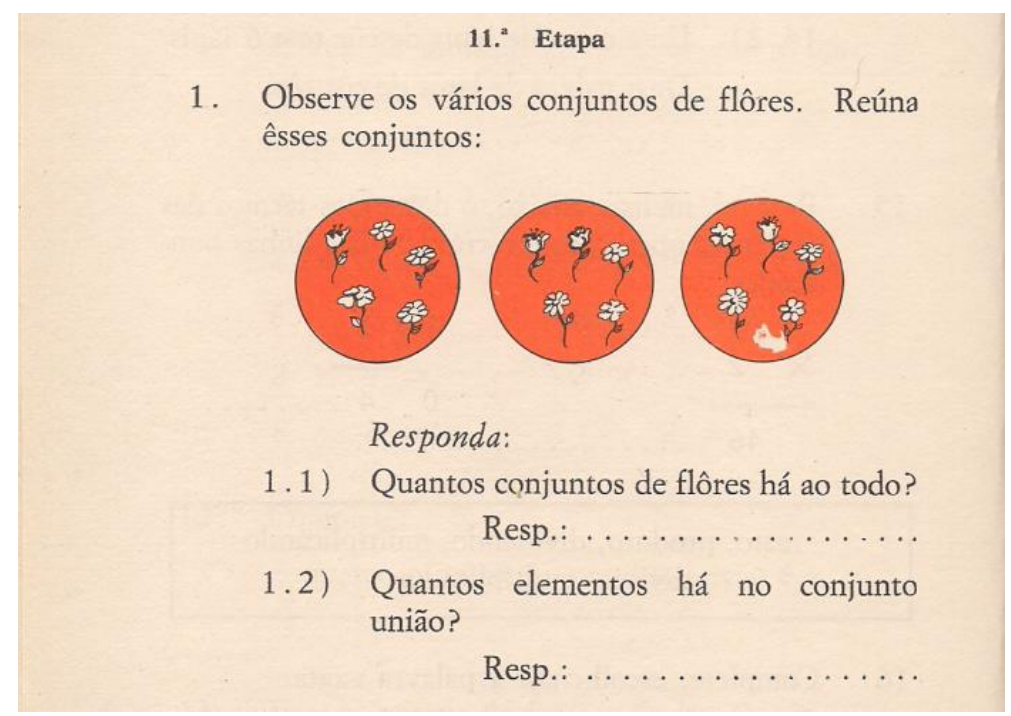

Fonte: Acervo do HISALES

Da mesma forma, foi mantida a proposta nos livros da coleção NTNG_2, o que pode ser conferido no exemplo da Figura 08, em que são apresentados quatro conjuntos com dois passarinhos representados em cada, que devem ser reunidos em um único conjunto, cujo total de elementos corresponde ao produto entre o número de conjuntos e número de imagens de passarinhos.

Figura 08 - NTNG_2 - 2 ${ }^{\mathrm{a}}$ série (1975, p. 95).

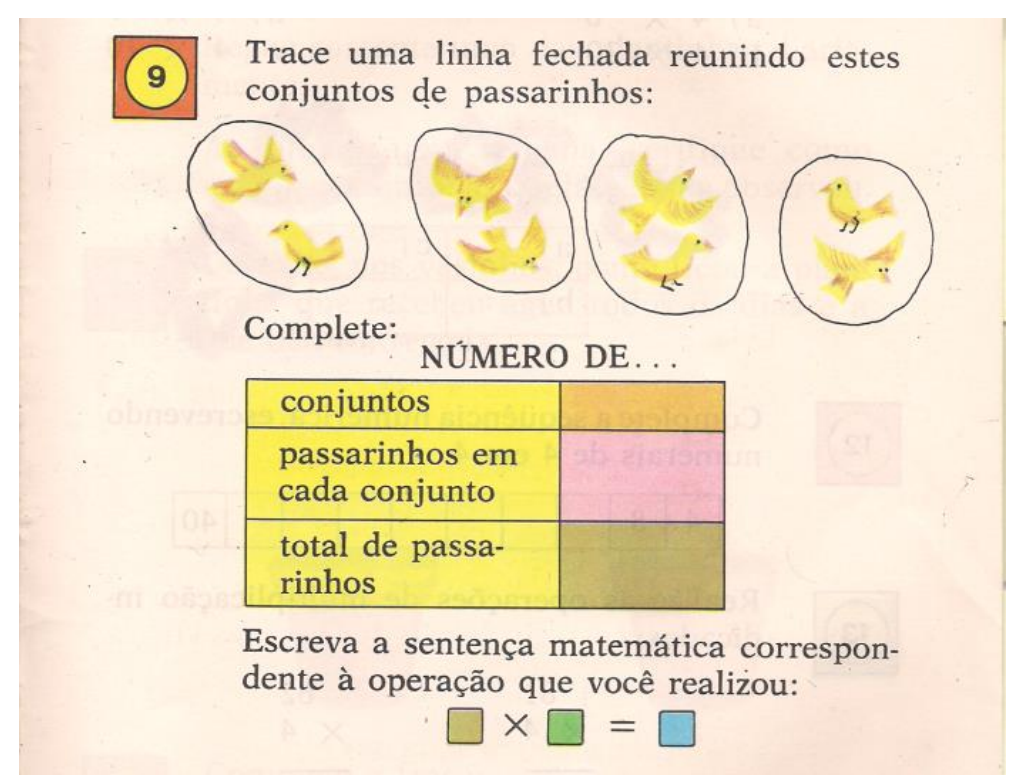

Fonte: Acervo do HISALES

$$
\text { ISSN 2526-2882 }
$$


Todos esses exemplos reforçam a tese de que a coleção NTNG_1 representa um período primeiro de aproximação com a Matemática Moderna. É preciso compreender que produzir livros didáticos, artefatos culturais próprios da cultura escolar, demanda arranjos que são da ordem editorial, mercadológica, política, pedagógica, etc. Por certo, Cecy e Nelly, experientes professoras-autoras, mantinham um diálogo constante com editores, planejadores, ilustradores, gestores, professores e alunos - usuários e destinatários finais nesse circuito do livro didático. Esse circuito, e as decisões que dele decorriam, ajuda a explicar essas mudanças e permanências nas três coleções aqui analisadas.

As autoras não tinham apenas que atender a uma nova demanda para/no ensino da Matemática, mas precisavam observar aspectos que eram da ordem do fazer editorial e do fazer pedagógico: como mercadoria o livro precisava vender (BATISTA, 2009), como artefato pedagógico precisa funcionar na prática. É preciso reafirmar que esse circuito, que inclui as demandas da prática, ajuda a explicar a diferença entre as três coleções. Analisando as coleções, percebe-se que entender o que funcionava em sala de aula, estava sempre no horizonte das autoras. No caso da coleção NTNG_2, a Matemática Moderna torna-se mais visível e aqueles vestígios de uma matemática tradicional são quase que completamente abandonados. Nesse aspecto, é preciso incluir a dimensão tempo, pois nenhuma "nova" proposta substitui uma "velha", de imediato. No campo educacional essa dimensão ganha ainda mais importância, ou seja, professoras e professores precisam de tempo para compreender, absorver, familiarizar-se com novas teorias, novas metodologias e mudanças de conteúdos. Possivelmente, as autoras gaúchas tivessem ciência, de alguma forma, desse processo.

Para além disso, elas mesmas estavam construindo referências dessa nova Matemática. Considero, também, que os livros expressam a negociação das autoras com os demais sujeitos produtores de livros, em especial os editores, lembrando que os autores não escrevem livros, mas textos que são transformados em livros pelos editores (CHARTIER, 2010). Seria, no mínimo, ingênuo pensar que as mudanças e permanências da abordagem dos conteúdos matemáticos nas três coleções fossem apenas decorrentes de uma opção das autoras, do fato de concordarem ou discordarem dos teóricos da Matemática Moderna, ou decorrente de uma simples transposição da teoria para a prática. Se assim fosse, seria por demais simplificador a compreensão do fenômeno da produção de livros didáticos e dos princípios da Matemática Moderna, expressos nas coleções em análise.

Os exemplos que foram e estão sendo apresentados precisam ser pensados em uma perspectiva mais ampla: da complexidade da produção didática. Nelly e Cecy, mulheresprofessoras, atentas ao seu tempo e ao espaço, não produziram as coleções motivadas pela adesão ou não ao Movimento da Matemática Moderna. De fato, produziram, fizeram suas 
escolhas, inseridas num circuito que supõe políticas editoriais e pedagógicas. É preciso observar que a Editora do Brasil, à época, anos 1960 e 1970, já havia se consolidado no mercado editorial como uma importante editora de livros didáticos, pois sua origem encontrava-se na produção desse tipo de livros, somando-se, assim, as escolhas das autoras à experiência dos profissionais dessa editora com os livros didáticos.

Retornando aos exemplos em foco e ainda para o caso da multiplicação, na coleção NTNG_2, os exercícios deixam de ser apresentados a partir de problemas na língua vernácula (como nas coleções EI e NTNG_1) e passam a ser sempre ilustrados com gravuras remetendo à Teoria dos Conjuntos. Identifiquei, nesses exercícios, que as mudanças realizadas nos livros a fim de atender às novas orientações para o ensino da Matemática no Ensino Primário acabam por determinar também um padrão de referência para a visualidade dos livros. Dessa forma se constituíram não apenas como um modelo pedagógico, mas também gráfico-editorial, revelando uma estreita relação entre as propostas pedagógicas e os aspectos gráficos na produção de livros didáticos (CHARTIER, 1994, 1996; FRADE, 2010).

A análise dos livros da coleção NTNG_2 permitiu identificar, ainda, uma outra proposta para o ensino da multiplicação, também por meio da Teoria dos Conjuntos, porém com o uso de uma nova operação: o produto cartesiano ${ }^{98}$. São apresentados, inicialmente, nos livros dessa coleção exercícios de produto cartesiano, sem relação com a operação de multiplicação, como se observa no exercício ilustrado na Figura 09.

Figura o9 - NTNG_2 - $2^{\text {a }}$ série (1975, p. 81).

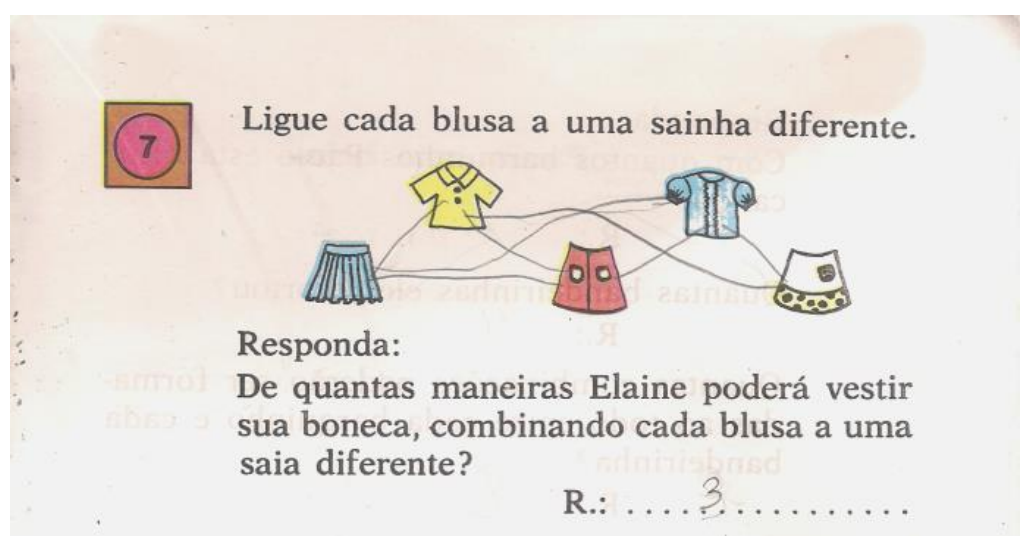

Fonte: Acervo do HISALES

A proposta desse exercício é levar o aluno a construir a ideia de multiplicação através da percepção de que o número de combinações possíveis entre "blusas e saias" pode ser

\footnotetext{
98 Produto cartesiano é uma operação realizada entre dois conjuntos não vazios A e B através da qual se origina um novo conjunto formado por todas as combinações possíveis entre os elementos de A e os elementos de B, nas quais o primeiro termo da combinação pertença ao conjunto $\mathrm{A}$ e o segundo termo ao conjunto $\mathrm{B}$, às quais chamamos de pares ordenados.
}

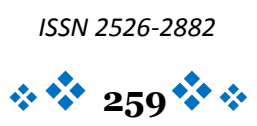


encontrado por meio de uma operação aritmética: a multiplicação. Porém, não há, no livro do aluno, explicitação em relação a isso, o que, possivelmente, levou o aluno a errar a resposta do exercício ${ }^{99}$.

Apesar de não haver relação explícita no livro do aluno entre o produto cartesiano proposto nos exercícios e a operação de multiplicação, existe a orientação aos professores, no Livro do Mestre, que estabelecessem essa relação:

O professor deverá oportunizar situações para que os alunos vivenciem a operação de multiplicação através do produto cartesiano. Poderão, por exemplo, recortar 2 bonecas de papel e 3 blusinhas, uma de mangas curtas, outra de mangas compridas e outra sem mangas. Experimentarão de quantas maneiras podem vestir as bonecas, de modo que as duas vistam todas as blusinhas, uma de cada vez. Após, relatarão as conclusões a que chegaram e representarão graficamente o que obsevaram. Muitas atividades como a sugerida deverão ser realizadas, até que os alunos possam responder às perguntas: Quantas bonecas? Quantas blusinhas? Quantas combinações foram feitas? (THOFEHRN, CUNHA, 1974, p. 28-29).

Interessante observar, primeiro, a condução diretiva sugerida, especialmente nas questões propostas; segundo, como a própria noção de ensino que subjaz é pautada no fazer, na experimentação; terceiro, ao analisar o Livro do Mestre de forma mais ampliada é evidenciada a função instrumental (CHOPPIN, 2004) dos livros didáticos, que pode ser identificada tanto na análise dos prefácios, quanto nas indicações de uso prescritas.

Na perspectiva das autoras, o professor deveria complementar a proposta do livro didático com outras atividades para que os alunos compreendessem a relação entre produto cartesiano e multiplicação. Orientam acerca disso e, embora propondo outros exercícios dessa natureza, dividem essa tarefa com o professor, pois, possivelmente, consideram que essa operação entre conjuntos apresentaria um nível maior de dificuldade para ser dominada pelos alunos.

O exercício 07, reproduzido na Figura 10, por exemplo, é um indício (GINZBURG, 2007) de que o aluno que o realizou não compreendeu exatamente que cada um dos "chapéus" representados no exercício poderia ser relacionado (ligado) ao menino e a menina. Indícios dessa natureza ajudam a revelar as possíveis dificuldades das crianças em assimilarem a ideia de multiplicação por meio do produto cartesiano.

\footnotetext{
99 Embora não esteja entre os objetivos desse trabalho analisar os usos do livro didático, não se pode evitar uma breve consideração acerca da resposta do aluno ao problema apresentado. É interessante observar que o aluno que utilizou esse livro, apesar de resolver corretamente a ligação entre blusas e saias errou a resposta da pergunta posta no exercício, cuja resolução é feita contando-se o número de ligações entre as blusas e saias, ou pelo produto do número de saias pelo número de blusas, nesse caso, por 2 × 3. Não compreendendo a ideia adjacente ao exercício o aluno respondeu erroneamente que o número de combinações possíveis para o problema é igual a 3, possivelmente considerando o número de combinações possíveis entre uma blusa e as saias representadas na imagem, o que resultaria em três possibilidades, indicando que o aluno não construiu a ideia de produto pelo exercício proposto.
} ISSN 2526-2882

\section{0}


Figura 10 - NTNG_2 - 2 ${ }^{\mathrm{a}}$ série (1975, p. 107).

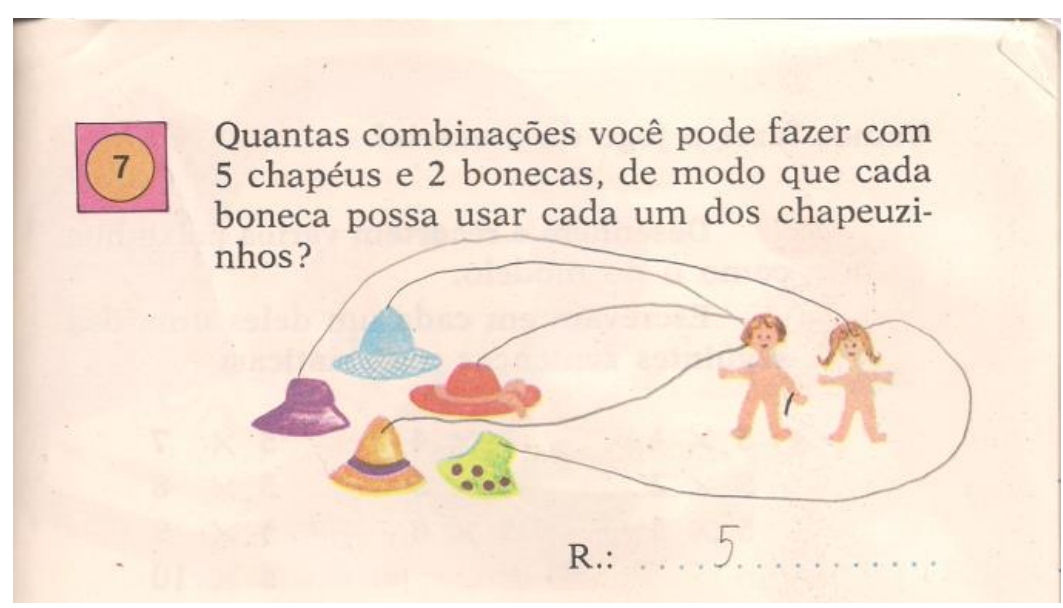

Fonte: Acervo do HISALES

Possivelmente, essa dificuldade resultou, também, na mescla de exercícios de multiplicação relacionados ao produto cartesiano (exercício 7) com aqueles nos quais a multiplicação corresponde à ideia de união, em um único conjunto, de dois ou mais conjuntos equivalentes, como no exercício 8 (Figura 11), de modo que os alunos poderiam entender essas duas relações entre conjuntos como a operação de multiplicação.

Figura 11 - NTNG_2 - $2^{\mathrm{a}}$ série $(1975$, p. 107).

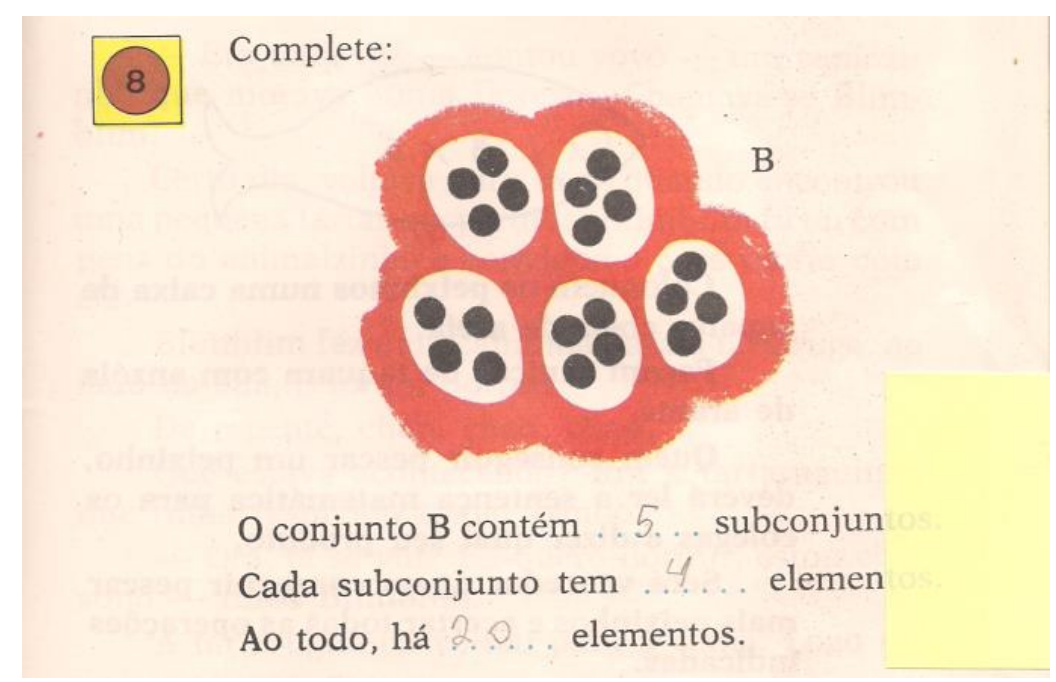

Fonte: Acervo do HISALES

Assim, mesmo não sendo objetivo deste texto analisar o uso do livro didático pelo aluno, não há como evitar a problematização do fato de que a proposta de desenvolver a multiplicação por meio do produto cartesiano apresenta-se menos eficaz do que por meio da ideia da repetição de conjuntos (grupos) com a mesma quantidade de elementos, pois, como 
se percebe na Figura 72, o aluno, usuário do livro didático, não conseguiu obter êxito na resolução do exercício 7 envolvendo produto cartesiano, mas compreendeu a ideia presente no exercício 8, acertando sua resolução.

\section{Conclusão}

Pelas leituras realizadas era esperada uma profunda mudança de abordagem nas operações aritméticas de uma coleção para outra, decorrentes da forte presença da Teoria dos Conjuntos nas novas propostas para o ensino da Matemática em todos os níveis de ensino, a partir do MMM.

Porém, apesar de a relação entre as operações de conjuntos e as operações aritméticas serem encontradas em todos os livros da coleção NTNG, há uma ênfase maior nos livros do $1^{\circ}$ e do $2^{\circ}$ ano do Ensino Primário, quando a multiplicação é proposta pela primeira vez. Essa relação é menos utilizada nos livros do $3^{\circ}, 4^{\circ}$ e $5^{\circ}$ anos do primário, sendo que nessas séries escolares a multiplicação foi, normalmente, apresentada no formato de exercícios de arme $e$ efetue, envolvendo números.

Há evidências da teoria piagetiana acerca do desenvolvimento cognitivo, pois no $1^{\mathrm{o}} \mathrm{e}$ $2^{\mathrm{O}}$ anos, em que a idade das crianças corresponde aos primeiros anos do estágio das operações concretas, momento em que o conceito de número está sendo construído, as autoras recorreram à Teoria dos Conjuntos para promover o estudo da multiplicação. Já nos anos finais desse estágio, quando, a princípio, a criança já teria compreendido a noção de número, o recurso utilizado foi a apresentação das operações de forma direta, em exercícios do tipo arme e efetue.

Ficou evidente um maior destaque da Teoria dos Conjuntos na apresentação dos conceitos das operações do que nos exercícios de fixação, indicando para um papel introdutório dessa teoria no que se refere ao estudo das operações aritméticas, o que pode ser relacionado aos estudos da Psicologia Genética sobre as formas de aprender. Assim, no que diz respeito à categoria definida como a relação entre operações aritméticas e operações entre conjuntos é possível afirmar, após a análise dos livros, que foram atendidas parcialmente às orientações do MMM sobre o estudo das operações aritméticas na coleção NTNG_1, revelando, assim, a apropriação das autoras em relação a esse princípio, presente no novo modelo pedagógico, para o ensino da Matemática.

\section{Referências}

BATISTA, A.A.G. O conceito de "livros didáticos". In: BATISTA, A.A.G; GALVÃO, A.M.O. (Org.). Livros escolares de leitura no Brasil: elementos para uma história. Campinas: Mercado de Letras, 2009, p. 41-73.

ISSN 2526-2882 
CERTEAU, M. A invenção do cotidiano: artes de fazer. Petrópolis: Vozes, 1998.

CHARTIER, R. A história cultural: entre práticas e representações. Lisboa: Difel, 1990.

. A ordem dos livros: leitores, autores e bibliotecas na Europa entre os séculos XIV e XVIII. Brasília: Ed. da UNB, 1994.

CHARTIER, Roger (org.). Práticas de Leitura. São Paulo: Estação Liberdade, 1996. . Escutar os mortos com os olhos. In: Estudos Avançados. São Paulo, v. 24, n. 69, p. 07-30, 2010.

CHOPPIN, A. O historiador e o livro escolar. Revista História da Educação. Pelotas, n. 11, Abril, 2002, p. 5-24.

CHOPPIN, Alain. História dos livros e das edições didáticas: sobre o estado da arte. Educação e Pesquisa. São Paulo, v. 30, n. 3, p. 549-566, set/dez. 2004.

DIENES, Z.P. A matemática moderna no ensino primário. Rio de Janeiro, Fundo de Cultura, 1967.

GINZBURG, C. Sinais: raízes de um paradigma indiciário. In: Mitos, emblemas, sinais: Morfologia e História. São Paulo: Companhia das Letras, 2007. p. 143-179.

PERES, E. Desenvolvimento do projeto de pesquisa Cartilhas Escolares em Pelotas (RS): organização do trabalho, fontes e questões de investigação. In: Frade, I.C.A.S; Maciel, Francisca IP. História da alfabetização: produção, difusão e circulação de livros (MG/RS/MT - Séc. XIX e XX). Belo Horizonte: UFMG/FaE, 2006, p. 117-144.

PIAGET, J; INHELDER, B. Gênese das estruturas lógicas elementares. Rio de Janeiro: Zahar Editores, 1975.

THOFEHRN, CC; CUNHA, N. Livro do Mestre. São Paulo: Editora do Brasil, 1974.

THOFEHRN, CC; CUNHA, N. Livro do Mestre. São Paulo: Editora do Brasil, 1975.

\section{Biografia Resumida}

Antônio Maurício Medeiros Alves: Licenciado em Matemática (UCPEL) e Pedagogia (UNINTER). Especialista em Educação Matemática (UCPEL). Mestre e doutor em Educação (UFPel). Professor Adjunto do Departamento de Educação Matemática do Instituto de Física e Matemática da Universidade Federal de Pelotas (UFPel/Pelotas/RS). Integrante dos grupos de pesquisas História da Alfabetização, Leitura, Escrita e dos Livros Escolares (HISALES/UFPel), Grupo de Pesquisa de História da Educação ISSN 2526-2882 
Matemática no Brasil (GHEMAT/Unifesp) e Líder do Grupo de

Estudos sobre Educação Matemática nos Anos Iniciais (GEEMAI/UFPel).

Link Lattes: http://Link Lattes.cnpq.br/3704006449718179 e-mail: alves.antoniomauricio@gmail.com 